\title{
Development of a novel biomarker model for predicting preoperative lymph node metastatic extent in esophageal squamous cell carcinoma ${ }^{1}$
}

\author{
Zhao Ma ${ }^{1, *}$, Xianxian Wu ${ }^{1, *}, \#$, Bo Xu ${ }^{2}$, Hongjing Jiang ${ }^{1}$, Peng Tang ${ }^{1}$, Jie Yue ${ }^{1}$, \\ Mingquan $\mathrm{Ma}^{1}$, Chuangui Chen ${ }^{1}$, Hongdian Zhang ${ }^{1}$ and Zhentao $\mathbf{Y u}^{1}$ \\ ${ }^{1}$ Department of Esophageal Cancer, Tianjin Medical University Cancer Institute and Hospital, Key Laboratory of Prevention \\ and Therapy of Tianjin, Tianjin's Clinical Research Center for Cancer, National Clinical Research Center of Cancer, Tianjin, \\ China \\ ${ }^{2}$ Department of Molecular Radiation Oncology, Tianjin Medical University Cancer Institute and Hospital, Tianjin, China \\ *These authors have contributed equally to this work \\ \# Co-first author \\ Correspondence to: Zhentao Yu, email: yuzhtao@hotmail.com \\ Keywords: esophageal squamous cell cancer; lymph node metastasis; biomarker; risk prediction; squamous cell carcinoma \\ antigen \\ Abbreviations: Esophageal squamous cell carcinoma (ESCC), Lymph node metastasis (LNM), Japanese Esophageal Society (JES), \\ A receiver operating characteristic (ROC), The area under the ROC curve (AUC) \\ Received: June 27, $2017 \quad$ Accepted: October 12, $2017 \quad$ Published: November 11, 2017 \\ Copyright: $\mathrm{Ma}$ et al. This is an open-access article distributed under the terms of the Creative Commons Attribution License 3.0 \\ (CC BY 3.0), which permits unrestricted use, distribution, and reproduction in any medium, provided the original author and source \\ are credited.
}

\section{ABSTRACT}

The number and range of lymph node metastasis (LNM) are critical prognostic factors in esophageal squamous cell carcinoma (ESCC). Preoperative serum biomarkers are reported to be associated with LNM. However, whether these markers can precisely predict the extent of LNM is not known. The aim of this study was to evaluate the predictive value of preoperative serum SCC-Ag, Cyfra21-1, CEA, CA199 and CA72-4 for LNM number and range by retrospectively investigating 577 ESCC patients undergone esophagectomy from 2007-2010. In this study, the positive rate of SCC-Ag and CA19-9 were associated with pN stage. Significant differences were found in CEA and CA19-9 between pN0-1 stage patients and pN2-3 stage patients. However, in subgroup analysis (patients with pNO-1), significant difference was found only in SCC-Ag between pNO and pN1 stage patients $(P=0.003)$. Middle thoracic ESCC patients were Chosen to analyze the correlation between the range of LNM and biomarkers. SCC-Ag was correlated with paraesophageal and paracardial lymph nodes, but not correlated with subcarinal and left gastric artery lymph nodes. Interestingly, the results of CEA were opposite to that of SCC-Ag. CA19-9 was associated with subcarinal and paracardial LNM $(P=0.000, P=0.038)$. Based on the results, a model incorporated SCC-Ag, CEA and CA19-9 was constructed. The rate of patients with pN2-3 stage was $15.4 \%$ and $54.4 \%$ in group 1 and 4 of our model.

In summary, SCC-Ag was associated with early lymph node metastatic stage, and CEA and CA19-9 have a close relationship with advanced lymph node metastatic stage. The model combining SCC-Ag, CEA and CA19-9 might help identify the preoperative extent of LNM for a subgroup of ESCC patients that can be benefited from neoadjuvant therapy. 


\section{INTRODUCTION}

The prognosis of esophageal squamous cell carcinoma (ESCC) depends on the clinical stage of the primary tumor and the extent of lymph node metastasis (LNM) [1]. Lymph node status could be classified by LNM number or stations based on the latest version of the UICC/AJCC TNM classification ( ${ }^{8}$ th edition)[2] or Japanese Classification of Esophageal Cancer $\left({ }^{11}\right.$ th edition) [3]. These two LNM classification methods define the extent of LNM by analyzing the metastatic number and range.

Serum biomarkers are biologic or biochemical substances that are produced by tumor cells, and are commonly used for identifying cancer, indicating treatment outcomes and predicting prognosis. In ESCC, it has been reported that preoperative biomarkers have a close relationship with tumor burden, including tumor invasion, LNM and the survival rate $[4,5]$. But there has been no studies focusing on the correlation between biomarkers and metastatic extent of lymph node which was more valuable for clinicians to evaluate operative indication.

Squamous cell carcinoma antigen (SCC-Ag), carcinoembryonic antigen (CEA), cytokeratin 19 fragments (Cyfra21-1), carbohydrate antigen 19-9 (CA199) and carbohydrate antigen 72-4 (CA724) are commonly used in the management of esophageal cancer patients. SCC-Ag and Cyfra21-1 are sensitive biomarkers in malignant disease, particularly in squamous cell carcinoma [6,7]. CEA, an oncofetal glycoprotein, is a representative biomarker that has been known to be elevated in almost all solid tumors, especially colorectal cancer [8]. In esophageal carcinoma, CEA has been reported as a diagnostic and prognostic marker $[9,10]$. CA199 and CA724 are elevated in a variety of cancers, especially gastrointestinal cancer [11-13].

In the present study, (1) we clarify which preoperative serum levels of the biomarkers were associated with LNM status. (2) SCC-Ag, Cyrfra21-1, CEA and CA19-9, which showed a significant correlation with LNM, were selected to evaluate the relationship with lymph node metastatic number and stations. (3) We analyzed the diagnostic values of the model incorporated preoperative serum SCC-Ag, CEA and CA19-9 for lymph node metastatic extent in ESCC.

\section{RESULTS}

\section{Patients and disease characteristics}

In 577 ESCC patients, the median age of the patients was 61 years (range, 27 to 82 years). The median and interquartile range of SCC-Ag, Cyfra21-1, CEA, CA19-9 and CA72-4 were $0.7 \mathrm{ug} / \mathrm{L}(0.4-1.3 \mathrm{ug} / \mathrm{L}), 2.36 \mathrm{ug} / \mathrm{L}(1.69-$ $3.26 \mathrm{ug} / \mathrm{L}), 2.19 \mathrm{ug} / \mathrm{L}(1.49-3.11 \mathrm{ug} / \mathrm{L}), 8.66 \mathrm{U} / \mathrm{ml}$ (5.06-
$15.92 \mathrm{U} / \mathrm{ml})$ and $1.30 \mathrm{U} / \mathrm{ml}(0.92-2.44 \mathrm{U} / \mathrm{ml})$. Baseline patient disease characteristics are shown in Table 1.

\section{The correlations between the preoperative serum biomarkers and LNM}

The positive rate of serum SCC-Ag, Cyfra21-1, CEA and CA19-9 were associated with LNM in the Chi-square test (Table 2; all $P<0.05$ ). Same statistically significant results were found when assessing the relation between the biomarkers level and LNM using the MannWhitney-U test (SCC-Ag, $P=0.000$; Cyfra21-1, $P=0.049$; CEA, $P=0.032$; CA19-9, $P=0.024$; CA72-2, $P=0.361$ ). On the multivariate analysis, SCC-Ag and CA19-9 were independent risk factors for LNM (Table 2; $P<0.05$ ).

\section{Correlations between preoperative serum biomarkers and LNM number}

SCC-Ag, Cyfra21-1, CEA and CA19-9 were chosen to analyze the correlations with $\mathrm{pN}$ stage. The positive rate of serum SCC-Ag and CA19-9 were associated with pN stage (Table 3; $P=0.010$ and $P=0.004$ ). To further examine the relationship between SCC-Ag, Cyfra21-1, CEA and CA19-9 and the LNM extent, patients with pN0 and pN1were selected (477 patients in total). In this subpopulation, the positive rate of SCC-Ag was much higher in $\mathrm{pN} 1$ stage patients compared to those in pN0 stage patients $(23.9 \%$ vs. $13.2 \%, P=0.003)$, but no correlations were found in Cyfra21-1, CEA and CA19-9 (all $P>0.05$ ). (Table 4).

For analyzing the advanced stage of LNM, patients were divided into two subgroups, pN0-1 and pN2-3. Patients with $\mathrm{pN} 0-1$ stage were considered earlier and less extensive LNM, while patients with pN2-3 stage were considered more extensive LNM. High positive rate of preoperative serum CEA and CA199 were associated with more extensive LNM ( $P=0.039, P=0.000$, respectively). However, no correlation was found in SCC-Ag $(\mathrm{P}=0.105)$ (Table 5).

\section{Correlations between preoperative serum biomarkers and LNM groups}

Japanese Classification of Esophageal Cancer (11th edition) [3] graded $\mathrm{pN}$ stage(JES) based on the LNM groups which were defined according to the location of the tumor. For middle thoracic ESCC, middle thoracic paraesophageal lymph nodes and paracardial lymph nodes were involved in pN1 (JES), subcarinal lymph nodes and left gastric artery lymph nodes were involved into $\mathrm{pN} 2$ (JES). pN2 (JES) stage was more extensive lymphatic invasion than $\mathrm{pN} 1$ (JES) stage.

In middle thoracic ESCC, the positive rate of SCC$\mathrm{Ag}$ was correlated with paraesophageal and paracardial lymph nodes in pN1 (JES) (all $P<0.05$ ), but not correlated 


\section{Characteristics}

Age, years

$\leq 60$

$>60$

Sex

Male

Female

Tumor location

Upper

Middle

Lower

Pathological T status

T1

$\mathrm{T} 2$

$\mathrm{T} 3$

$\mathrm{T} 4 \mathrm{a}$

$\mathrm{T} 4 \mathrm{~b}$

Pathological N status

N0

N1

$\mathrm{N} 2$

N3

Tumor Grade

Grade 1

Grade 2

Grade 3

TNM stage

I

IIA

IIB

IIIA

IIIB

IIIC

SCC-Ag

Positive (> $1.5 \mathrm{ug} / \mathrm{L}$ )

Negative $(\leq 1.5 \mathrm{ug} / \mathrm{L})$

Cyfra21-1

Positive (> $3.3 \mathrm{ug} / \mathrm{L}$ )

Negative $(\leq 3.3 \mathrm{ug} / \mathrm{L})$
No. of patients $(\%)$

$(\mathrm{N}=577)$

$$
274(47.5 \%)
$$

$303(52.5 \%)$

$476(82.5 \%)$

$101(17.5 \%)$

$45(7.8 \%)$

$396(68.6 \%)$

$136(23.6 \%)$

21 (3.6\%)

$105(18.2 \%)$

235 (40.7\%)

157 (27.2\%)

$59(10.2 \%)$

$310(53.7 \%)$

167 (28.9\%)

73 (12.7\%)

27 (4.7\%)

$21(3.6 \%)$

468 (81.1\%)

88 (15.3\%)

$21(3.7 \%)$

$44(7.6 \%)$

$180(31.2 \%)$

139 (24.1\%)

$33(5.7 \%)$

$160(27.7 \%)$

$102(17.7 \%)$

$463(80.2 \%)$

140 (24.3\%)

437 (75.7\%) 
CEA

$$
\text { Positive ( }>5 \mathrm{ug} / \mathrm{L} \text { ) }
$$

Negative ( $\leq 5 \mathrm{ug} / \mathrm{L})$

CA19-9

Positive (>39 U/ml)

Negative $(\leq 39 \mathrm{U} / \mathrm{ml})$

CA72-4

Positive (> $6 \mathrm{U} / \mathrm{ml})$

Negative $(\leq 6 \mathrm{U} / \mathrm{ml})$
$37(6.4 \%)$

$540(93.6 \%)$

$23(4.0 \%)$

$554(96.0 \%)$

$46(8.0 \%)$

$531(92.0 \%)$ with subcarinal and left gastric artery lymph nodes in $\mathrm{pN} 2$ (JES). Interestingly, the association between the positive rate of CEA and LNM groups were opposite to that in SCC-Ag. Significant results of CEA were found in $\mathrm{pN} 2$ group (JES) (all $P<0.05$ ) and not in pN1 group (JES). The positive rate of serum CA19-9 was associated with subcarinal and paracardial LNM $(P=0.000, P=0.038)$ (Table 6).

\section{A biomarkers diagnostic model and risk groups to LNM}

To better identify ESCC patients at high risk for LNM, we proposed a new diagnostic model by combining SCC-Ag, CEA and CA19-9, and stratified patients into four groups. Grade 1 group: negative SCC-Ag, CEA and CA19-9; Grade 2 group: positive SCC-Ag, negative CEA and negative CA19-9; Grade 3 group: negative SCC-Ag with positive CEA or positive CA19-9 or both; Grade 4 group: positive SCC-Ag with positive CEA or positive CA19-9 or both. In the patients reported here, there are $422,91,41$ and 11 patients in the grade 1, 2, 3 and 4 groups, respectively. With this model, the analysis showed the rate of patients with pN2-3 stage in ESCC was 15.4\% in grade 1 group. The rate of LNM patients was $81.8 \%$ and the rate of patients with pN2 -3 stage was $54.5 \%$ in grade 4 group. ROC curve analyses were performed, the area under the ROC curve (AUC) in predicting LNM with this model was $0.567(P=0.006)$. The AUC in predicting LNM extent with this model was $0.563(P=0.048)$ (Supplementary Figure 1) (Table 7).

\section{DISCUSSION}

To our knowledge, our report is the largest published retrospective study to date that analyzes the correlation between preoperative serum biomarkers (SCC-Ag, Cyfra21-1, CEA, CA19-9 and CA72-4) and LNM in
ESCC. More importantly, there have been no studies investigating the predictive values of these preoperative serum biomarkers to the extent of LNM. The present study found that the serum SCC-Ag, CEA and CA19-9 were closely associated with lymph node metastatic extent. Different serum biomarkers revealed different stages of LNM. The model we built will help predict LNM and further define the precise status of $\mathrm{pN}$ stage (N0-1 or N2$3)$.

ESCC has a high prevalence in Asia and easily metastasizes to lymph nodes. Neoadjuvant therapy, especially preoperative chemoradiation therapy, could downstage the tumor, significantly reduce the 3-year mortality and locoregional recurrence compared with surgery alone [15-17]. The clinical value of preoperative lymph node status identification is to decide whether patients should undergo neoadjuvant therapy first. Diagnostic imaging techniques, including computed tomography and endosonography, have limitation that cannot predict lymph node status sufficiently. Preoperative serum biomarkers, which are measured routinely prior to treatment, could provide information of LNM based on our study presented here.

SCC-Ag and Cyfra21-1 are sensitive biomarker in malignant disease, particularly in squamous carcinoma $[6$, 7]. In ESCC, the positive rate of SCC-Ag and Cyfra21-1 previously reported were $25.2 \%-38 \%[4,18-20]$ and $17.7 \%-47.8 \%[5,20]$. In our study, the positive rate of SCC-Ag and Cyfra21-1 were $18.1 \%$ and $24.3 \%$. Different positive rates of these biomarkers might result from different proportion of TNM stage and detected method. Previous studies have indicated that SCC-Ag was correlated with LNM in head and neck, cervical, penile and anal canal cancer [21-24]. In esophageal cancer, except LNM, elevated SCC-Ag was also associated with tumor size, depth of tumor invasion, TNM stage and poor survival rate $[4,5,25]$. Similar results were observed in this study and SCC-Ag was an independent risk factor for 
Table 2: Univariate and multivariate logistic regression analysis for correlation between clinical and biological characteristics and lymph node metastasis in 577 cases

\begin{tabular}{|c|c|c|c|c|c|c|}
\hline \multirow{2}{*}{ Biomarkers } & \multicolumn{2}{|c|}{ Lymph node metastasis } & \multicolumn{2}{|c|}{ Univariate analysis } & \multicolumn{2}{|c|}{ Multivariate analysis } \\
\hline & Negative & Positive & $\chi^{2}$ & $P$ value & OR & $P$ value \\
\hline \multicolumn{7}{|l|}{ Age, years } \\
\hline$\leq 60$ & 140 & 134 & 1.267 & 0.260 & NA & NA \\
\hline$>60$ & 169 & 134 & & & & \\
\hline \multicolumn{7}{|l|}{ Sex } \\
\hline Male & 247 & 229 & 3.020 & 0.082 & NA & NA \\
\hline Female & 62 & 39 & & & & \\
\hline \multicolumn{7}{|c|}{ Tumor location } \\
\hline Upper & 25 & 20 & 0.347 & 0.841 & NA & NA \\
\hline Middle & 214 & 182 & & & & \\
\hline Lower & 70 & 66 & & & & \\
\hline \multicolumn{7}{|c|}{ Pathological T status } \\
\hline $\mathrm{T} 1$ & 19 & 2 & 22.590 & 0.000 & - & 0.106 \\
\hline $\mathrm{T} 2$ & 66 & 39 & & & & \\
\hline $\mathrm{T} 3$ & 124 & 111 & & & & \\
\hline $\mathrm{T} 4 \mathrm{a}$ & 70 & 87 & & & & \\
\hline $\mathrm{T} 4 \mathrm{~b}$ & 30 & 29 & & & & \\
\hline \multicolumn{7}{|l|}{ Tumor Grade } \\
\hline Grade 1 & 17 & 4 & 10.810 & 0.004 & & \\
\hline Grade 2 & 254 & 214 & & & 3.881 & 0.019 \\
\hline Grade 3 & 38 & 50 & & & 6.096 & 0.003 \\
\hline \multicolumn{7}{|l|}{ Tumor length } \\
\hline$\leq 3 \mathrm{~cm}$ & 94 & 43 & 16.382 & 0.000 & 2.198 & 0.000 \\
\hline$>3 \mathrm{~cm}$ & 215 & 225 & & & & \\
\hline $\mathrm{SCC}-\mathrm{Ag}$ & 263 & 201 & 10.138 & 0.001 & 1.917 & 0.005 \\
\hline Negative & 40 & 62 & & & & \\
\hline \multicolumn{7}{|l|}{ Positive } \\
\hline Cyfra21-1 & & & 4.566 & 0.033 & - & 0.116 \\
\hline Negative & 245 & 192 & & & & \\
\hline Positive & 64 & 76 & & & & \\
\hline CEA & & & 3.925 & 0.048 & - & 0.241 \\
\hline Negative & 295 & 245 & & & & \\
\hline Positive & 14 & 23 & & & & \\
\hline CA19-9 & & & 7.265 & 0.007 & 3.612 & 0.010 \\
\hline Negative & 303 & 251 & & & & \\
\hline Positive & 6 & 17 & & & & \\
\hline CA72-4 & & & 2.040 & 0.153 & NA & NA \\
\hline Negative & 289 & 242 & & & & \\
\hline Positive & 20 & 26 & & & & \\
\hline
\end{tabular}

NA, not available (not included in multivariate analysis). 
Table 3: Correlation between biomarkers and pN stage in 577 ESCC patients

\begin{tabular}{|c|c|c|c|c|c|c|c|c|c|c|c|c|}
\hline \multirow{2}{*}{$\begin{array}{l}\text { pN } \\
\text { stage }\end{array}$} & \multicolumn{2}{|c|}{ SCC-Ag } & \multirow{2}{*}{$\begin{array}{c}P \\
\text { value }\end{array}$} & \multicolumn{2}{|c|}{ Cyfra21-1 } & \multirow{2}{*}{$\begin{array}{c}P \\
\text { value }\end{array}$} & \multicolumn{2}{|c|}{ CEA } & \multirow{2}{*}{$\begin{array}{c}P \\
\text { value }\end{array}$} & \multicolumn{2}{|c|}{ CA19-9 } & \multirow{2}{*}{$\begin{array}{c}P \\
\text { value }\end{array}$} \\
\hline & Negative & Positive & & Negative & Positive & & Negative & Positive & & Negative & Positive & \\
\hline N0 & 263 & 40 & 0.010 & 246 & 64 & 0.065 & 296 & 14 & 0.137 & 306 & 6 & 0.004 \\
\hline N1 & 124 & 39 & & 122 & 45 & & 155 & 12 & & 161 & 6 & \\
\hline $\mathrm{N} 2$ & 57 & 15 & & 53 & 20 & & 67 & 8 & & 66 & 7 & \\
\hline N3 & 19 & 8 & & 16 & 11 & & 24 & 3 & & 23 & 4 & \\
\hline
\end{tabular}

Table 4: Correlation between biomarkers and early stage lymph node metastasis in 477 pN0-1 stage patients

\begin{tabular}{|c|c|c|c|c|c|c|c|c|c|c|c|c|}
\hline \multirow{2}{*}{$\begin{array}{l}\mathrm{pN} \\
\text { stage }\end{array}$} & \multicolumn{2}{|c|}{ SCC-Ag } & \multirow{2}{*}{$\begin{array}{c}P \\
\text { value }\end{array}$} & \multicolumn{2}{|c|}{ Cyfra21-1 } & \multirow{2}{*}{$\begin{array}{c}P \\
\text { value }\end{array}$} & \multicolumn{2}{|c|}{ CEA } & \multirow{2}{*}{$\begin{array}{c}P \\
\text { value }\end{array}$} & \multicolumn{2}{|c|}{ CA19-9 } & \multirow{2}{*}{$\begin{array}{c}P \\
\text { value }\end{array}$} \\
\hline & Negative & Positive & & Negative & Positive & & Negative & Positive & & Negative & Positive & \\
\hline N0 & 263 & 40 & 0.003 & 246 & 64 & 0.118 & 296 & 14 & 0.221 & 304 & 6 & 0.270 \\
\hline N1 & 124 & 39 & & 122 & 45 & & 155 & 12 & & 161 & 6 & \\
\hline
\end{tabular}

Table 5: Correlation between biomarkers and advanced stage lymph node metastasis in 577 ESCC patients

\begin{tabular}{lcccc}
\hline Tumor markers & $\begin{array}{c}\text { N0-1 } \\
(\mathbf{L N M} \leq \mathbf{2})\end{array}$ & $\begin{array}{c}\mathbf{N 2 - 3} \\
(\mathbf{L N M}>\mathbf{2})\end{array}$ & $\boldsymbol{\chi}^{\mathbf{2}}$ & $\boldsymbol{P}$ value \\
\hline SCC-Ag & 387 & 76 & 2.176 & 0.140 \\
$\quad$ Negative & 79 & 23 & & \\
Positive & & & 2.987 & 0.084 \\
Cyfra21-1 & 368 & 69 & & $\mathbf{0 . 0 3 9}$ \\
Negative & 109 & 31 & 4.242 & \\
Positive & & & & $\mathbf{0 . 0 0 0}$ \\
CEA & 451 & 89 & 15.548 & \\
Negative & 26 & 11 & & \\
Positive & & & & \\
CA19-9 & 465 & 11 & & \\
Negative & 12 & & & \\
Positive & & & & \\
\hline
\end{tabular}

LNM. We also examined SCC-Ag in pN0-1 stage patients (LNM number $\leq 2$ ) which could analyze early stage lymph node metastatic status. In this subgroup, only SCC-Ag was associated with LNM $(P=0.003)$ and its specificity was $86.8 \%$. Although Cyfra 21-1, CEA and CA19-9 were associated with LNM in ESCC, they do not serve as precise predictors for early stage LNM.

There is a controversy for categorizing pathological $\mathrm{N}$ stage based on UICC/AJCC TNM classification or Japanese Classification of Esophageal Cancer. These two methods represent different aspects of LNM extent.
Larger number or range of LNM stands for more extensive metastasis and later stage. Among the 4 biomarkers, only high positive rate of CEA and CA19-9 were demonstrated to associate with advanced stage LNM. There was no significant difference for SCC-Ag $(P=0.140)$. These results showed SCC-Ag would be elevated at early stage of LNM and could predict early LNM status. On the contrary, CEA and CA19-9 could predict advanced LNM status.

It should be noted that our purpose to analyze the correlation between lymph node stations and biomarkers was not to predict the specific lymph node station 
Table 6: Correlation between biomarkers and lymph node metastatic groups in 396 middle thoracic ESCC

\begin{tabular}{|c|c|c|c|c|c|c|c|c|c|}
\hline \multirow{2}{*}{ Tumor marker } & \multicolumn{2}{|c|}{ SCC-Ag } & \multirow{2}{*}{$\begin{array}{c}P \\
\text { value }\end{array}$} & \multicolumn{2}{|c|}{ CEA } & \multirow{2}{*}{$\begin{array}{c}P \\
\text { value }\end{array}$} & \multicolumn{2}{|c|}{ CA19-9 } & \multirow{2}{*}{$\begin{array}{c}P \\
\text { value }\end{array}$} \\
\hline & Negative & Positive & & Negative & Positive & & Negative & Positive & \\
\hline $\begin{array}{l}\text { middle thoracic } \\
\text { paraesophageal lymph nodes }\end{array}$ & & & 0.012 & & & 0.963 & & & 0.559 \\
\hline Negative & 267 & 51 & & 301 & 23 & & 311 & 13 & \\
\hline Positive & 49 & 20 & & 67 & 5 & & 68 & 4 & \\
\hline \multicolumn{10}{|l|}{ paracardial lymph nodes } \\
\hline Negative & 284 & 52 & 0.000 & 322 & 23 & 0.415 & 333 & 12 & 0.038 \\
\hline Positive & 32 & 19 & & 46 & 5 & & 46 & 5 & \\
\hline \multicolumn{10}{|l|}{ subcarinal lymph nodes } \\
\hline Negative & 281 & 59 & 0.174 & 327 & 21 & 0.030 & 338 & 10 & 0.000 \\
\hline Positive & 35 & 12 & & 41 & 7 & & 41 & 7 & \\
\hline \multicolumn{10}{|l|}{ left gastric artery lymph nodes } \\
\hline Negative & 265 & 53 & 0.067 & 307 & 19 & 0.037 & 314 & 12 & 0.195 \\
\hline Positive & 51 & 18 & & 61 & 9 & & 65 & 5 & \\
\hline
\end{tabular}

Table 7: The discriminatory value of diagnostic model for lymph node metastatic extent in 577 ESCC patients

\begin{tabular}{|c|c|c|c|c|c|c|c|c|}
\hline \multirow{2}{*}{ Diagnostic model } & \multicolumn{2}{|c|}{ Lymph node metastasis } & \multirow{2}{*}{$\chi^{2}$} & \multirow{2}{*}{$\begin{array}{c}P \\
\text { value }\end{array}$} & \multicolumn{2}{|c|}{ Lymph node metastasis extent } & \multirow{2}{*}{$\chi^{2}$} & \multirow{2}{*}{$\begin{array}{c}P \\
\text { value }\end{array}$} \\
\hline & Negative & Postitive & & & N0-1 & N2-3 & & \\
\hline Grade 1 group & $244(57.8 \%)$ & $178(42.2 \%)$ & \multirow{4}{*}{15.240} & \multirow{4}{*}{0.002} & $357(84.6 \%)$ & $65(15.4 \%)$ & \multirow{4}{*}{14.287} & \multirow{4}{*}{0.003} \\
\hline Grade 2 group & $38(41.8 \%)$ & $53(58.2 \%)$ & & & $74(81.3 \%)$ & $17(18.7 \%)$ & & \\
\hline Grade 3 group & $18(43.9 \%)$ & $23(56.1 \%)$ & & & $30(73.2 \%)$ & $11(26.8 \%)$ & & \\
\hline Grade 4 group & $2(18.2 \%)$ & $9(81.8 \%)$ & & & $5(45.5 \%)$ & $6(54.5 \%)$ & & \\
\hline
\end{tabular}

metastatic status with markers. In Japanese Classification of Esophageal Cancer, some specific lymph node stations stand for more extensive metastasis. To confirm our thoughts above, we chose middle thoracic esophageal carcinoma patients and analyzed the status of middle thoracic paraesophageal lymph nodes (pN1, JES) and paracardial lymph nodes (pN1, JES), subcarinal lymph nodes ( $\mathrm{pN} 2, \mathrm{JES}$ ), and left gastric artery lymph nodes (pN2, JES). Interestingly, SCC-Ag was significantly associated with pN1 (JES) stage LNM $(P<0.05)$, but not pN2 (JES) stage $(P>0.05)$. Opposite relationships with lymph node stations were found in CEA. Similar results of CA19-9 were verified in the thoracic lymph node stations. In abdominal lymph node stations, CA19-9 was correlated with paracardial LNM. A probable reason for this discrepancy may be explained as follows. Wang et al. [26] argued that most patients had abdominal LNM accompanied by thoracic (mediastinal) LNM at the same time and the 5-year survival rate was lower than that of patients with thoracic LNM. CA19-9 could not indentify well in abdominal LNM whose lymph metastasis extent was more severe compared with thoracic LNM.

The positive rate of CEA in ESCC ranges from 9.1\% to $23 \%[4,18,27]$. CEA has been reported to own the function of an adhesion molecule. CEA- containing tumor cells could preferentially go into metastatic cascade [28, 29]. Kosugi et al.[4] reported that CEA had no correlation with LNM, but with distant metastasis in ESCC. However, another study revealed significant differences were found between CEA and LNM in ESCC [18]. CA19-9 is also called sialylated Lewis Antigen which is speculated to play roles in the extravasation of cancer cells from blood and the promotion of metastatic spread to distant organs [30]. CA19-9 was widely used in pancreatic cancer, colon cancer, gastric cancer, and other gastrointestinal tumors $[11,12,31-33]$. In a meta-analysis of gastric cancer, there were the correlation between elevated CA19-9 and LNM, $\mathrm{T}$ stage, TNM stage, vessel invasion and poor survival 
rate [34]. In ESCC, Zhao et al. [31] first reported CA19-9 with a new cutoff value was associated with LNM and hematogenic metastasis. Our study reveals that elevated CEA and CA19-9 are associated with advanced stage of LNM.

Together with previous findings, our study provided a LNM predictive model, which could help identify the extent of LNM. Patients with advanced stage LNM, which was classified into III stage or above (based on UICC/ AJCC TNM classification), are recommended to undergo preoperative chemoradiotherapy or chemotherapy first.

Several limitations to our study exist. Since the analyses were performed retrospectively on a single institutional database, selection biases might be underestimated. Additional validation of the models using different data sets might further prove the clinical value of the model.

In conclusion, this study demonstrates the correlation between LNM and the positive rate of preoperative serum SCC-Ag, Cyfra21-1, CEA and CA19-9. SCC-Ag was associated with early lymph node metastatic stage. CEA and CA19-9 have a close relationship with advanced lymph node metastatic stage. The model incorporated SCC-Ag, CEA and CA19-9 could further increase the predictive value for the LNM status of esophageal squamous cell carcinoma.

\section{MATERIALS AND METHODS}

\section{Patients and eligibility criteria}

Among patients with esophageal squamous cell carcinoma undergone esophagectomy in Cancer Institute and Hospital of Tianjin Medical University from January 2007 to December 2010, the study was conducted on 577 patients whose preoperative serum SCC-Ag, Cyfra21-1, CEA, CA19-9 and CA72-4 were examined. The cases exclude from the current study based on the following criteria: (1) patients who had history of malignant disease; (2) patients who had received preoperative treatment (chemotherapy and/or radiotherapy); (3) patients who had other malignant tumors except esophageal squamous carcinoma.

The serum Cyfra21-1, CEA, CA19-9 and CA724 were detected within 7 days before surgery with electrochemiluminescence immunoassay (Roche Elecsys E170, Germany). The SCC-Ag was detected by chemical luminescence immunoassay (Abbott Architect i2000, America). The normal upper limit was $1.5 \mathrm{ug} / \mathrm{L}, 3.3 \mathrm{ug} / \mathrm{L}$, $5 \mathrm{ug} / \mathrm{L}, 39 \mathrm{U} / \mathrm{ml}$ and $6 \mathrm{U} / \mathrm{ml}$ for SCC-Ag, Cyfra21-1, CEA, CA19-9 and CA72-4 respectively. The esophagectomy with 2- to 3-field lymph node dissection was taken for standard treatment. The depth of primary tumor, degree of lymph node ( $\mathrm{pN}$ stage) and TNM staging were defined according to UICC/AJCC TNM classification (7th edition)[14]. For analyzing the relationship between lymph node metastatic range and biomarkers, the LNM grading method of Japanese Classification of Esophageal Cancer (11th edition) [3] also were used and defined as "pN stage (JES)". JES is the abbreviation for Japanese Esophageal Society. In present study, we defined pN1 and pN2-3 (UICC/AJCC TNM classification or Japanese Classification of Esophageal Cancer) as early stage and advanced stage LNM to analyze the correlation between biomarkers and LNM extent.

\section{Statistical analysis}

The statistical analyses were performed with the SPSS 21.0 software (ver. 21 SPSS Inc., Chicago, IL). The correlations between serum level of biomarkers and clinicopathological characteristics were assessed using the Chi-square or Mann-Whitney-U test. Significant risk factors identified by univariate analysis were further assessed by multivariate analysis using logistic regression. A receiver operating characteristic (ROC) curve was constructed. $P<0.05$ was considered statistically significant.

\section{Author contributions}

Conceived and designed the study: Zhao Ma and Zhentao Yu. Wrote the manuscript: Zhao Ma. Clinical data colletion: Xianxian Wu, Jie Yue, Mingquan Ma and Hongdian Zhang. Statistical analyses: Hongjing Jiang, Peng Tang and Chuangui Chen. Carried out critical revision of the manuscript: $\mathrm{Bo} \mathrm{Xu}$.

\section{CONFLICTS OF INTEREST}

The authors declare no conflicts of interest.

\section{FUNDING}

This work was supported by the fund from National Key Clinical Specialist Construction Programs of China (NO. 2013-544), Key Grant of Health and Family Planning Commission of Tianjin (14KG143) and Chinese Ministry of Science and Technology (2016YFC0904600).

\section{REFERENCES}

1. Cense HA, van Eijck CH, Tilanus HW. New insights in the lymphatic spread of oesophageal cancer and its implications for the extent of surgical resection. Best Pract Res Clin Gastroenterol. 2006; 20:893-906.

2. Rice TW, Ishwaran H, Ferguson MK, Blackstone EH, Goldstraw P. Cancer of the esophagus and esophagogastric junction: an eighth edition staging primer. J Thorac Oncol. 2017; 12:36-42. 
3. Japanese Classification of Esophageal Cancer, 11th Edition: part I. Esophagus-Tokyo. 2017; 14:1-36.

4. Kosugi S, Nishimaki T, Kanda T, Nakagawa S, Ohashi M, Hatakeyama K. Clinical significance of serum carcinoembryonic antigen, carbohydrate antigen 19-9, and squamous cell carcinoma antigen levels in esophageal cancer patients. World J Surg. 2004; 28:680-685.

5. Cao X, Zhang L, Feng GR, Yang J, Wang RY, Li J, Zheng XM, Han YJ. Preoperative Cyfra21-1 and SCC-Ag serum titers predict survival in patients with stage II esophageal squamous cell carcinoma. J Transl Med. 2012; 10:197.

6. Mroczko B, Kozlowski M, Groblewska M, Lukaszewicz M, Niklinski J, Jelski W, Laudanski J, Chyczewski L, Szmitkowski M. The diagnostic value of the measurement of matrix metalloproteinase 9 (MMP-9), squamous cell cancer antigen (SCC) and carcinoembryonic antigen (CEA) in the sera of esophageal cancer patients. Clin Chim Acta. 2008; 389:61-66.

7. Stieber P, Hasholzner U, Bodenmuller H, Nagel D, SunderPlassmann L, Dienemann H, Meier W, Fateh-Moghadam A. CYFRA 21-1. A new marker in lung cancer. Cancer. 1993; 72:707-713.

8. Perkins GL, Slater ED, Sanders GK, Prichard JG. Serum tumor markers. Am Fam Physician. 2003; 68:1075-1082.

9. Zhang HQ, Wang RB, Yan HJ, Zhao W, Zhu KL, Jiang SM, $\mathrm{Hu}$ XG, Yu JM. Prognostic significance of CYFRA21-1, CEA and hemoglobin in patients with esophageal squamous cancer undergoing concurrent chemoradiotherapy. Asian Pac J Cancer Prev. 2012; 13:199-203.

10. Yi Y, Li B, Wang Z, Sun H, Gong H, Zhang Z. CYFRA21-1 and CEA are useful markers for predicting the sensitivity to chemoradiotherapy of esophageal squamous cell carcinoma. Biomarkers. 2009; 14:480-485.

11. Kornek GV, Depisch D, Rosen HR, Temsch EM, Scheithauer W. Comparative analysis of CA72-4, CA195 and carcinoembryonic antigen in patients with gastrointestinal malignancies. J Cancer Res Clin Oncol. 1992; 118:318-320.

12. Polat E, Duman U, Duman M, Atici AE, Reyhan E, Dalgic T, Bostanci EB, Yol S. Diagnostic value of preoperative serum carcinoembryonic antigen and carbohydrate antigen 19-9 in colorectal cancer. Curr Oncol. 2014; 21 :e1-e7.

13. Liang Y, Wang W, Fang C, Raj SS, Hu WM, Li QW, Zhou ZW. Clinical significance and diagnostic value of serum CEA, CA19-9 and CA72-4 in patients with gastric cancer. Oncotarget. 2016; 7:49565-49573. https://doi.org/10.18632/ oncotarget.10391.

14. Edge SB, Compton CC. The American Joint Committee on Cancer: the 7th edition of the AJCC cancer staging manual and the future of TNM. Ann Surg Oncol. 2010; 17:1471-1474.

15. Shapiro J, van Lanschot JJ, Hulshof MC, van Hagen P, van Berge HM, Wijnhoven BP, van Laarhoven HW, Nieuwenhuijzen GA, Hospers GA, Bonenkamp JJ,
Cuesta MA, Blaisse RJ, Busch OR, et al. Neoadjuvant chemoradiotherapy plus surgery versus surgery alone for oesophageal or junctional cancer (CROSS): long-term results of a randomised controlled trial. Lancet Oncol. 2015; 16:1090-1098.

16. Urschel JD, Vasan H. A meta-analysis of randomized controlled trials that compared neoadjuvant chemoradiation and surgery to surgery alone for resectable esophageal cancer. Am J Surg. 2003; 185:538-543.

17. Sjoquist KM, Burmeister BH, Smithers BM, Zalcberg JR, Simes RJ, Barbour A, Gebski V. Survival after neoadjuvant chemotherapy or chemoradiotherapy for resectable oesophageal carcinoma: an updated meta-analysis. Lancet Oncol. 2011; 12:681-692.

18. Lukaszewicz-Zajac M, Mroczko B, Kozlowski M, Niklinski J, Laudanski J, Szmitkowski M. Higher importance of interleukin 6 than classic tumor markers (carcinoembryonic antigen and squamous cell cancer antigen) in the diagnosis of esophageal cancer patients. Dis Esophagus. 2012; 25:242-249.

19. Zhang J, Zhu Z, Liu Y, Jin X, Xu Z, Yu Q, Li K. Diagnostic value of multiple tumor markers for patients with esophageal carcinoma. PLoS One. 2015; 10:e116951.

20. Ikeguchi M, Kouno Y, Kihara K, Suzuki K, Endo K, Nakamura S, Sawada T, Shimizu T, Matsunaga T, Fukumoto Y, Saito H. Evaluation of prognostic markers for patients with curatively resected thoracic esophageal squamous cell carcinomas. Mol Clin Oncol. 2016; 5:767-772.

21. Ferrandina G, Macchia G, Legge F, Deodato F, Forni F, Digesu C, Carone V, Morganti AG, Scambia G. Squamous cell carcinoma antigen in patients with locally advanced cervical carcinoma undergoing preoperative radiochemotherapy: association with pathological response to treatment and clinical outcome. Oncology. 2008; 74:42-49.

22. Williams M, Swampillai A, Osborne M, Mawdsley S, Hughes R, Harrison M, Harvey R, Glynne-Jones R. Squamous cell carcinoma antigen: a potentially useful prognostic marker in squamous cell carcinoma of the anal canal and margin. Cancer. 2013; 119:2391-2398.

23. Huang SF, Wei FC, Liao CT, Wang HM, Lin CY, Lo S, Huang JJ, Chen IH, Kang CJ, Chien HT, Chen HH. Risk stratification in oral cavity squamous cell carcinoma by preoperative CRP and SCC antigen levels. Ann Surg Oncol. 2012; 19:3856-3864.

24. Li ZS, Yao K, Li YH, Chen JP, Deng CZ, Zhao Q, Chen P, Wang B, Mi QW, Liu ZW, Qin ZK, Han H, Zhou FJ. Clinical significance of preoperative C-reactive protein and squamous cell carcinoma antigen levels in patients with penile squamous cell carcinoma. BJU Int. 2016; 118:272-278.

25. Shimada H, Nabeya Y, Okazumi S, Matsubara H, Shiratori T, Gunji Y, Kobayashi S, Hayashi H, Ochiai T. Prediction of survival with squamous cell carcinoma antigen in patients 
with resectable esophageal squamous cell carcinoma. Surgery. 2003; 133:486-494.

26. Chen G, Wang Z, Liu XY, Zhang MY, Liu FY. Abdominal lymph node metastasis in patients with mid thoracic esophageal squamous cell carcinoma. World J Surg. 2009; 33:278-283.

27. Shimada Y, Watanabe G, Kawamura J, Soma T, Okabe $\mathrm{M}$, Ito $\mathrm{T}$, Inoue $\mathrm{H}$, Kondo $\mathrm{M}$, Mori Y, Tanaka E, Imamura M. Clinical significance of osteopontin in esophageal squamous cell carcinoma: comparison with common tumor markers. Oncology. 2005; 68:285-292.

28. Lee DS, Kim YS, Jung SL, Lee KY, Kang JH, Park S, Kim YK, Yoo I, Choi BO, Jang HS, Yoon SC. The relevance of serum carcinoembryonic antigen as an indicator of brain metastasis detection in advanced non-small cell lung cancer. Tumour Biol. 2012; 33:1065-1073.

29. Feng F, Sun L, Liu Z, Liu S, Zheng G, Xu G, Guo M, Lian X, Fan D, Zhang H. Prognostic values of normal preoperative serum cancer markers for gastric cancer. Oncotarget. 2016; 7:58459-58469. https://doi.org/10.18632/ oncotarget.11248.
30. Nakamura H, Nishimura T. History, molecular features, and clinical importance of conventional serum biomarkers in lung cancer. Surg Today. 2017; 47:1037-1059.

31. Zhao H, Chen W, Wu J, Wang L, Mao W. Clinical significance of preoperative serum tumor markers in esophageal squamous cell carcinoma. J Cancer Res Ther. 2014; 10:C179-C185.

32. Liu L, Xu H, Wang W, Wu C, Chen Y, Yang J, Cen P, Xu J, Liu C, Long J, Guha S, Fu D, Ni Q, et al. A preoperative serum signature of CEA+/CA125+/CA19-9 >/= $1000 \mathrm{U} / \mathrm{mL}$ indicates poor outcome to pancreatectomy for pancreatic cancer. Int J Cancer. 2015; 136:2216-2227.

33. Wang JK, Hu HJ, Shrestha A, Ma WJ, Yang Q, Liu F, Cheng NS, Li FY. Can preoperative and postoperative CA19-9 levels predict survival and early recurrence in patients with resectable hilar cholangiocarcinoma? Oncotarget. 2017; 8:45335-45344. https://doi.org/10.18632/oncotarget.17336.

34. Song YX, Huang XZ, Gao P, Sun JX, Chen XW, Yang YC, Zhang C, Liu HP, Wang HC, Wang ZN. Clinicopathologic and prognostic value of serum carbohydrate antigen 19-9 in gastric cancer: a meta-analysis. Dis Markers. 2015; 2015:549843. 